\title{
A Study on the Phased Objectives and Major Measures of the Coordinated Development of Beijing, Tianjin and Hebei
}

\author{
Wang Jianfeng ${ }^{1,}$ a*$^{*}$, Lu Yan², Zhao Tiantian ${ }^{3}$ \\ ${ }^{1}$ School of Economics and Management, Beijing Jiaotong University, Beijing, China \\ ${ }^{2}$ Business School, Hebei University of Economics and Trade, Shijiazhuang, China \\ ${ }^{3}$ Business School, Hebei University of Economics and Trade, Shijiazhuang, China \\ $a^{*}$ wang22jianfeng@163.com
}

\begin{abstract}
In 2014, the coordinated development of Beijing, Tianjin and Hebei has become a national strategy and entered a new stage. In 2015, the outline of Beijing Tianjin Hebei coordinated development plan was released, marking the preliminary completion of the top-level design of coordinated development. In 2017, Xiongan New Area was established, and the coordinated development of Beijing, Tianjin and Hebei entered a key stage of comprehensive promotion and key breakthrough. During the 13th Five Year Plan period Beijing, Tianjin and Hebei regional cooperation has achieved a good start, but also faces new challenges, and deep-seated problems in key areas still need to be solved. This paper analyzes problems in the coordinated development of Beijing, Tianjin and Hebei since the 13th Five-year Plan, and puts forward the goals, major tasks and key measures of the coordinated development of Beijing, Tianjin and Hebei during the 14th Five Year Plan period Combined with the actual development of Beijing, Tianjin and Hebei.
\end{abstract}

Keywords: Beijing, Tianjin and Hebei, the 14th Five Year Plan, major tasks, key measures

\section{京津冀协同发展阶段性目标和重大举措研究}

\author{
王建峰 $1, \mathrm{a}^{*}$ 卢燕 2 赵甜甜 ${ }^{3}$
}

${ }^{1}$ 北京交通大学经济管理学院, 北京, 中国

${ }^{2}$ 河北经贸大学商学院, 石家庄, 河北, 中国

${ }^{3}$ 河北经贸大学商学院, 石家庄, 河北, 中国

$a^{*}$ wang22jianfeng@163. com

\section{摘要}

2014 年京津冀协同发展上升为国家战略，协同发展迈入新的阶段; 2015 年《京津冀协同发展规划纲要》 发布，标志着协同发展顶层设计初步完成； 2017 年雄安新区成立，京津冀协同发展进入全面推进、重 点突破的关键阶段。“十三五” 时期, 京津冀区域协同实现了良好开局, 同时也面临着新的挑战, 重 点领域深层次问题仍待破解。本文通过梳理 “十三五” 以来京津冀协同发展取得的进展与成效，分析 京津冀协同发展存在的问题，结合京津冀发展实际，探讨提出 “十四五” 时期京津冀协同发展的目标、 重大任务与重点举措。

关键词: 京津冀，“十四五”目标，重大任务，重点举措

\section{1. 京津冀协同发展的进展、成效与问题}

\section{1. 进展与成效}

近年来，围绕京津冀协同发展纲要，京津冀在经济 社会、制度建设、非首都功能疏解、产业、交通、公共 服务、生态、协作创新平台建设等方面均取得了重要突 破。

顶层设计和创新协同机制不断趋于深化。京津冀三 
地从顶层设计出发, 出台了多项政策文件, 落实《京津 冀协同发展规划纲要》的文件和规划密集出台, 编制重 点领域、重点区域总体规划; 京津冀协同创新共同体不 断推进，全面推进国家级战略性创新平台建设，区域间 技术转移日趋活跃, 2014 年至 2018 年, 河北吸纳京津 技术交易额 601.38 亿元，占全省的 $52.19 \%$ 。

北京有序疏解非首都功能取得阶段性进展。北京常 住人口呈现增量、增速双下降, 2018 年北京常住人口为 2154.2 万人, 较去年下降了 $0.8 \%$; 存量疏解有序进行、 增量管控严格有效, 动物园、大红门等区域性批发市场 完成撤并升级和外迁, 制定实施全国首个以治理 “大城 市病”为目标的新增产业禁限目录并两次修订完善。

“两翼” 建设成效明显。城市副中心通州作为北京 “一翼” ，建设步入快车道，北京市级行政中心迁入， 交通和基础设施建设投资力度大; 雄安新区既是北京 “一翼”，又是河北 “一翼” ，其规划建设已从顶层设 计和规划编制转向实质性建设阶段; 张北地区作为河北 未来发展的 “一翼”, 张家口立足 “两区”（首都水源 涵养功能区和生态环境支撑区）建设, 建设规划正式印 发, 引导河北绿色发展。

产业协同发展深入推进。产业结构趋于高级化和合 理化, 京津冀三次产业构成由 2014 年的 5.2:41.3:53.5 调整为 2018 年的 4. 3: 34. 4: 61.3, 第三产业比重提高 7.8 个百分点, 三地的高新技术产业、战略性新兴产业 都发展迅速; 承接产业转移平台建设有序进行, “4 $4 \mathrm{~N}$ ” 产业合作格局更加巩固 ${ }^{[1]}$ 。

交通一体化领域取得突破性进展。轨道交通网加快 建设, 我国首条智能高铁京张高铁实现全线轨道贯通, 京津城际延长线、津保、张唐等铁路建成通车; 公路交 通网不断完善, 2018 年京津冀公路里程合计 23.1 万公 里, 比 2014 年增加 1.4 万公里; 世界级机场群正在形 成, 北京大兴机场全面竣工, 2018 年京津冀机场群完成 旅客吞吐量 14499.7 万人次, 较上年增长 $7.7 \%$ 。

生态环境质量得到明显改善。环境污染治理不断加 强, 2018 年, 京津冀大气中 PM2. 5 平均浓度 55 微克/ 立方米, 比 2014 年下降 40. 9\%, 京津冀三地监测的地表 水, 水质优良比例分别为 $54.5 \% 、 40 \% 、 48.6 \%$, 均比上 年升高了至少 5 个百分点, 劣 $\mathrm{V}$ 类水质比例分别为 $21.0 \% 、 25 \% 、 20.3 \%$, 均比上年降低了至少 13 个百分点; 生态保护与建设有序推进, 北京森林覆盖率已达到 $43.5 \%$, 天津五年来共完成营造林 238 万亩左右, 林木 绿化率提高了 $23.7 \%$, 河北 2018 年共完成营造林 987.6 万亩，为年度任务目标的 $107.7 \%$ 。

公共服务均等化取得一定进展。教育医疗合作深入 开展, 京津冀 296 家试点医疗机构对 33 项临床检验结 果实现互认, 北京累计与津冀开展教育帮扶项目 60 余 项; 就业与社会保障有序衔接, 京津冀人力资源服务地 方标准实现统一, 工伤认定现场调查核实、伤残等级鉴 定结果实现互认; 对口帮扶工作升级加力, 北京与张家 口、承德、保定三市 23 个贫困县 (区) 建立结对帮扶 关系, 天津 5 个区与承德市 5 个县建立 “一对一” 结对 帮扶机制。

城市体系构建与城市空间布局有序进行。以“一核、
双城、三轴、四区、多节点”为骨架的空间布局持续推 进; 唐山、石家庄、保定、秦皇岛、张家口、衡水、邯 郸等市完成行政区划调整, 城市规模逐渐扩大; 把固安、 永清、派州等 15 个县市建设成特色鲜明、设施完善、 生态宜居、品位一流、服务首都的功能性小城市。

\section{2. 存在的问题}

自《京津冀协同发展规划纲要》实施以来, 京津冀 协同发展取得了较大进展。但京津冀协同发展仍存在若 干难点问题, 这些问题的妥善解决对京津冀协同发展至 关重要。

北京非首都功能疏解与承接缺乏全产业链视阈。一 是区域层面产业链缺链、断链严重, 优势互补的产业链 条尚待培育，仅就河北而言，其上游产业，如关键原材 料、重要核心技术缺失，下游产业，如金融服务业不发 达，产品消费信贷服务供给不足，导致工业制成品销售 渠道不通畅; 二是全产业链布局规划平台缺失, 各类承 接平台差距大、布局散、发展目标重叠, 产业疏解与对 接信息不对称现象突出, 无法实现精准对接, 转移和承 接通道尚未打通。

京津冀区域内各主体的利益关系问题。京津冀协同 发展的核心问题是利益协调问题，京津冀不仅包括三个 省级行政区，也是中央政府及其机关部门的集中所在 地, 利益协调问题涉及各方利益, 协调彼此之间的利益 关系一直非常棘手, 追根溯源是区域利益协调机制尚未 健全。此外, 京津冀跨流域、跨地区的协调工作始终没 有形成有效机制。如果没有京津冀及中央政府各方均比 较满意的利益协调机制, 京津冀协同发展的效果就会大 打折扣。

河北与京津在经济发展和公共服务水平方面存在 的断崖式落差。2018 年, 河北省会石家庄的 GDP 仅为北 京的 $20.1 \%$ 、天津的 $32.3 \%$, 河北人均 GDP 仅为北京的 $34.1 \%$ 、天津的 $39.6 \%$; 在教育方面, 河北每万人里普通 中学平均在校生数是北京 2.7 倍、天津的 2 倍, 而河北 每万人里普通高等学校平均在校生数仅是北京的 $66 \%$ 、 天津的 $53 \%$, 每万人里研究生平均在校生数仅是北京的 $4 \%$ 、天津的 15\%，河北的基础教育面临人多、压力大等 问题; 在医疗卫生方面, 从每万人医疗卫生机构数上看, 京津分别为 5.15、3.65 个，河北为 11.26 个，而从每 千人拥有卫生技术人员数上看, 河北不足北京的一半, 河北医疗卫生机构虽数量多，但规模小、医疗卫生服务 能力弱。

河北在促进京津冀协同发展中存在的产业、科技创 新和人才短板。河北产业主要集中于产业链的中低端, 缺乏有效的高端产业, 制造业方面, 具有高技术含量、 高附加值的高端产品领域相对薄弱, 服务业方面, 面向 制造业的生产性服务业以及面向居民高层次消费需求 的高端服务业发展很不充分 ${ }^{[2]}$; 河北科技创新能力弱, 北京技术专利成果向河北的转化力度不足, 2018 年河北 吸纳京津科技成果仅占两市输出总额的 $5.86 \%$, 比例仍 较低; 河北人才紧缺, 2017 年北京 $R \& D$ 人员中的本科人 
数、硕士人数、博士人数分别是河北的 2.1 倍、 2.9 倍、 10.1 倍。

环境治理和生态建设任务依然艰巨。大气污染防治 工作十分严峻，按照环境空气质量综合指数评价，2018 年环境空气质量排名倒数十名里河北占到了 5 个城市; 水资源量短缺, 2017 年, 京津冀水资源总量仅占全国的 $0.63 \%$ ，人均水资源量分别是全国的 $6.6 \% 、 4.1 \% 、 8.9 \%$ 。

京津冀城市群的城市体系与空间布局不合理。河北 新型城镇化进程相对缓慢, 全省城镇化率水平为 56. 43\%, 仍低于全国城镇化率 59.58\%, 比北京、天津分 别低 30.07 个和 26.72 个百分点; 河北缺乏与京津综合 服务能力和辐射带动能力相匹配并在全国具有重要影 响力的次级中心城市, 与京津间的落差和断层非常明 显, 石家庄对冀中南区域的辐射带动能力仍然不足 ${ }^{[3]}$ 。

建设 “轨道上的京津冀” 有待进一步加强。现阶段 区域道路交通体系的完善主要围绕北京为核心来打造, 北京仍面临较大的过境交通压力 ${ }^{[4]}$; 部分城市之间轨道 交通极为不便, 如京承、津承、石承、石沧、石廊等; 河北城市轨道交通落后, 仅有石家庄已建成部分轨道交 通。

河北省企业大规模关停与经济增长的矛盾日益突 出。大量钢铁、煤炭、石化等污染物排放企业由于环境 问题被关停限产，造成河北经济发展受到冲击; 相关部 门环境政策朝令夕改, 动不动就对企业 “一律关停” , 导致原本可以通过整改、技改等方式就达到环境标准的 企业无奈之下实施易地搬迁, 使企业对于河北市场没有 稳定预期, 不敢在河北投资, 进一步影响河北经济发展 前景。

\section{2. 京津冀协同发展阶段性目标}

\section{1. “十四五”发展目标}

有序疏解北京非首都功能取得根本进展。北京产业 疏解基本完成, 河北各地特色产业明显, 产业转型升级 取得重大进展, 承接产业精准, 能够高效、科学地实现 产业疏解与承接; 社会公共服务机构等疏解稳步进行, 按照疏解要求部分高校或分校、部分医院或分院、康复 和养老服务机构, 以及部分不必一定在京的党政军机构 全部得到合理疏解; 承接平台建设完善, “ $2+4+46$ ” 疏 解平台建设进入成熟期, 在办理落户、住房保障、子女 入学等方面提供专项支持, 实现全覆盖。

提高河北省整体竞争力, 继续推进河北 “三区一基 地” 建设。培育一批具有竞争力的大型物流园区或枢纽, 与各节点城市物流形成网络, 打造智慧物流体系 ${ }^{[5]}$; 提 高产业科技含量, 优化产业布局, 产业转型升级取得突 破性进展; 持续提高城镇化率, 每年力争提升 $1 \%$; 在治 理大气污染的同时全地域开展环境保护, 将承德、保定、 雄安新区作为试点进行生态保护修复。

北京城市副中心、雄安新区与张北地区建设取得明 显成效。北京城市副中心通州打造城市副中心一亦庄新
城（通州部分）-镇-新型农村社区的空间体系, 副中心 与周边特色小镇相互支撑, 建设高质量的绿色空间; 雄 安新区作为非首都功能集中承载地和首都功能拓展区, 城市布局基本完成, 创新型产业体系初步构建 ${ }^{[6]}$; 张北 地区充分利用 2022 年冬奥会契机, 加强与北京的互动, 带动一批大型项目建设, 发挥巨大潜能, 完善区域生态 信息共享与补偿机制 ${ }^{[7]}$ 。

科技成果转化率提升, 创新共同体建设取得突破性 进展。加快科技资源的交流融合, 提高资源使用效率, 搭建资源共享、技术研究合作与技术转移、产业合作的 平台, 共建共享一批大型项目 ${ }^{[8]}$, 逐年提高京津在河北 的科技成果转化率, 河北省吸纳京津科技成果占比例力 争 “十四五” 末达到 10\%, 河北省科技进步贡献率力争 “十四五”末达到 65\%以上。

生态环境明显好转, 跨界环境治理和保护取得显著 成效。资源节约集约利用水平继续提高; 空气质量持续 变好, PM2. 5 平均浓度等指数下降至少 $50 \%$; 低碳循环 经济发展形成较大规模, 单位生产总值平均能耗继续降 低至少 $10 \%$; 全面推行垃圾分类, 解决垃圾污染问题, 区域可持续发展能力不断增强。从保障雄安新区和首都 北京生态安全着眼, 推进生态综合治理, 实现京津冀绿 色发展。

京津冀协同发展体制机制更加完善。建立健全有利 于吸引京津资源要素共享的制度安排, 行成目标同向、 措施一体、作用互补、利益相连的体制机制。完善京津 冀生态补偿机制、基础设施和公共服务的成本分摊机 制、产业协同的利益分享机制以及人才和知识产权一体 化机制等, 建立起有效的京津冀利益协调机制, 促进体 制机制改革深入推进。

\section{2. 远期目标}

到 2035 年, 雄安新区基本建成绿色低碳、信息智 能、宜居宜业、具有较强竞争力和影响力、人与自然和 谐共生的高水平社会主义现代化城市 ${ }^{[9]}$ 。京津冀世界级 城市群已然形成, 北京发展为符合首都功能定位的国际 化大都市; 天津进入后工业化时期, 实现第三产业的跨 越; 河北各市更加突出产业特色, 第二产业高端化, 第 三产业进入高速增长阶段。京津冀三地间实现产业发展 一体化: 优势产业的产业链条完整, 形成网络发展态势; 三地形成合理的产业布局, 各地产业特色凸显, 形成各 自的支柱产业; 形成环绕北京的产业新城, 实现产城融 合。河北将与京津一道基本实现现代化和区域一体化, 成为生产要素流动顺畅配置高效、产业城市分工合理协 作紧密、基础设施互联互通便捷高效、公共服务体系一 体化建设均等共享, 经济发达、生态优美、生活幸福的 现代化世界级都市圈, 成为全国最具国际竞争力的区 域。 
环境污染治理和资源再生利用, 大力发展环保产业, 促

\section{3. 京津冀协同发展的重大任务}

\section{1. 精准承接, 深入推进北京非首都功能疏解}

加强政府引导与支持, 优化承接环境。继续加强区 域间政府沟通，提高工作效率; 重视各类规划，各类新 区、开发区、园区需要重视规划的制定、实施，并在权 限范围内给予一定的自由权, 使承接地建设贴合实际; 提高各级政府的主动服务意识, 有创新思维, 各级政府 需要探索创新模式, 提高积极主动性 ${ }^{[10]}$ 。

完善公共服务体系, 吸引疏解产业。在教育、医疗、 贸易审批等方面给予便利, 利用网络的便利, 打通信息 渠道, 实现信息共享, 做产业发展的坚强后盾 ${ }^{[11]}$; 创新 公共服务供给模式, 推进公共服务市场化改革, 完善京 津冀公共财政体系, 推动一批公共服务重点项目建设。

优化基础设施建设。基础设施建设是承接产业的首 要条件，吸引产业落地就要尽快破解土地与资金困境, 创新投融资模式，引入社会资本，支持承接地的基础设 施完善, 如实现开发区供水、排水、供电、道路、供气、 供热、通讯、宽带网络、有线电视和土地平整等 “九通 一平” 的基础设施建设; 打造四通八达的交通网络; 提 升新区基础设施配置标准等, 为引进产业提供基础条 件。

以全产业链布局推进产业承接平台建设。河北的产 业链条需借助产业的承接与转移, 引导京津创新资源落 地, 促进承接产业与当地产业发展互补, 从单向产业疏 解走向区域全产业链条布局; 统一谋划承接平台功能定 位, 避免同质化和重复建设, 围绕资源、地缘优势, 明 晰承接重点, 形成区域内错位发展、各有特色的产业集 群，实现错位承接和精准对接。

\section{2. 全面提高河北发展质量与速度}

提升河北产业实力。推进产业转型升级, 通过生产 要素改进、结构改变、生产效率与产品质量提高、产业 链升级等实现产业合理化与高级化; 进一步明确各地区 产业定位, 进行地域细化、产品细化, 依托资源优势, 打造各地特色; 促进河北产业科技创新发展, 加快协同 创新共同体建设, 充分利用京津创新资源, 提升产业创 新能力。

完善城镇网络布局。确定梯队增长极发展战略, 以 石家庄、唐山为第一梯队，廊坊、保定、邯郸、沧州、 秦皇岛为第二梯队, 张家口、邢台、承德、衡水为第三 梯队, 充分打造河北经济增长极, 形成依次带动经济发 展的可持续态势; 培育环首都特色卫星城镇, 把三河、 大厂、香河、固安、永清、溷州等一批县城 (县级市市 区) 建设成特色鲜明、设施完善、生态宜居、品位一流、 服务首都的功能性小城市 ${ }^{[12]}$ 。

加大力度治理环境污染。构建全方位的京津冀生态 环境防护安全网, 构建 “点” “线” “面”相结合的全 方位京津冀生态环境防护安全网, 优化生态空间, 推进 进节能减排，建立相应的运行机制，为优化环境提供支 持; 落实严格的水资源保护制度, 进一步加强水资源节 约保护和开发利用，提高水资源利用率。

以雄安、张北为 “两翼” 提升河北发展速度与质量。 高标准建设雄安新区, 集聚京津创新要素资源, 建设成 为技术研发、成果孵化的京津冀创新科技高地，高端人 才、创新要素的集聚地 ${ }^{[13]}$; 围绕构建京津冀生态环境支 撑区, 高质量建设张北地区, 充分发挥绿色引领作用。

\section{3. 继续加快京津冀协同发展步伐, 实现全面 一体化}

继续推进交通一体化。以交通圈为主体统筹规划交 通方式的有效衔接，利用公路、铁路、航空等方式共同 打造 “北京 1 小时交通圈”、“雄安 1 小时交通圈”、

“石家庄 2 小时交通圈” 的多中心交通网络系统; 提高 智能化水平，提高路况预报和交通信息化智能水平，最 大限度地提升交通效率; 彻底解决断头路问题, 推进京 津冀区县之间直通路的打通，为打造智能化、立体化、 网络化交通体系打通最后关节。

完善京津冀协同发展的体制机制。通过全面深化改 革, 不断加强体制机制的创新, 合理进行各级顶层设计, 明确思路、深入推进，在国家统筹指导下，重构三地协 同发展的政策体系，持续深化京津冀政策层面的对接交 流，健全常态化共建、共商、共享的高层联系机制，及 时梳理协同发展中的障碍，推动京津冀的协同发展。

\section{4. 京津冀协同发展的重点举措}

\section{1. 围绕 “疏解北京非首都功能”, 规划京津 冀全产业链布局}

从京津冀区域层面科学规划、布局产业链条, 实现 三地间产业优势互补。一是综合考虑京津冀区域各产业 的发展优劣势，科学规划各产业在不同区域的布局及发 展方向, 指引 “北京非首都功能” 产业能够有序外移、 平稳落地 ${ }^{[14]}$; 二是积极推进 “多规合一”，有效缓解各 级政府规划、不同产业园区之间规划目标交叠、冲突现 象, 对于河北来讲, 省级和市级的各种类型规划要对接 《京津冀协同发展规划纲要》, 力争保持地区发展规划 与各级规划的高度一致性; 三是成立 “产业疏解与对接” 服务平台，及时发布北京有疏解意愿或者投资意向的单 位信息，在有意向疏解的产业部门和各承接平台之间形 成随时沟通、相互了解的体制机制, 提高精准对接度。

\section{2. 强化京津冀协同发展对河北的支持力度}

“十四五”时期强化京津冀协同发展对河北的支 
项目落地，鼓励和引导金融机构对符合条件的产业转移 项目提供信贷支持, 在风险可控的前提下为京津冀地区 企业并购、重组提供支持; 四是提升企业市场化水平, 降低国有企业领导团队行政化与官员化程度，在市场准 入、金融支持、培育创新、权益保障等多方面共同发力 提升民营企业市场化水平。

\section{5. 进一步完善京津䩀城市体系, 加速新型城 镇化步伐}

京津冀城市体系中, 作为省会城市, 石家庄理应担 负起带动冀中南发展的核心增长极功能, 但是以石家庄 目前的发展水平, 无法引领该区域的发展, 也影响了京 津冀发展的平衡性和稳定性。此外, 雄安新区的设立, 对保定发挥优势、建设创新驱动的经济强市有着重要的 引领作用。因此, 在河北城市体系方面, 一是要做强省 域中心城市, 建议石家庄、唐山、保定、期䣋应主动提 高自身实力和带动力, 着力打造各自的城市圈, 形成自 身的辐射带动作用; 二是要提升京津周边中小城市能 级, 应积极推动中小城市的建设, 巩固和发展小城市实 力, 促进潜力好的小城市向中等城市转变, 以便形成合 理有序的规模结构 ${ }^{[19]}$ 。

\section{6 . 综合治理机制, 改善京津䩀发展的资源环 境}

改善京津冀发展的资源环境, 一是实施大气、水、 土壤等污染的综合治理; 二是推进京津冀山水林田湖海 生态治理工程, 依托交通通道、河道、山系等建设区域 性的生态廊道, 推进 “五湖 (白洋淀、衡水湖、七里海、 南大港、北大港） 六河（永定河、㴒河、北运河、南 运河、潮白河）一海（渤海）” 的生态修复和廊道建设, 特别是加大对白洋淀、海河等重点河湖水域的生态综合 治理; 三是完善京津冀生态补偿机制, 建立生态补偿基 金, 建立多元化补偿模式, 完善京津冀生态补偿机制和 生态补偿的法律法规。

\section{7. 继续推进京津冀交通一体化}

一是推进连接雄安新区与京津及周边其他城市、北 京新机场之间的轨道交通网络建设, 前瞻布局雄安新区 至冀中南和沿海地区的轨道交通 ${ }^{[20]}$; 二是建设高效富集 轨道交通网, 加快环京县市与北京之间的轨道交通街 接, 规划建设北京到承德、天津到承德、石家庄到承德、 石家庄到廊坊、石家庄到沧州的快捷高效客运通道, 实 现区域内快速铁路覆盖所有地级及以上城市; 三是建设 以沿海内河港口为节点、以铁路内陆车站为辐射、以公 路运输为补充的高效顺畅的公铁水、江海河联运系统, 积极推进干线铁路、城际铁路、市域铁路等引入机场, 提升机场集疏运能力。 
"Beijing-Tianjin-Hebei ecological environment support zone"[J].Journal of Chongqing University (social science edition), 2018, 24(03):38-45.

[8] Bo wenguang, Liu yang, Li jiayu. A study on the development of Beijing-Tianjin-Hebei collaborative innovation community[J]. Regional Economic Review, 2019(03): 139-146.

[9] Fan hengshan etc. Development of urban agglomeration: new features, new ideas and new directions[J]. Regional Economic Review, 2017(05): $1-25$.

\section{项目基金}

本文为河北省社会科学基金项目 “雄安新区创新体 系建设与创新型产业培育研究” (项目编号: HB19YJ025) 的阶段性成果之一。

\section{REFERENCES}

[1] Sun jiuwen, Xia tian. On the key tasks of coordinated development of Beijing, Tianjin and Hebei in the new era[J].Journal of Beijing Administrative College, 2018(05): 15-24.

[2] Jin lu, Wang zheng. A study on the development stage and countermeasures of Beijing-Tianjin-Hebei building a world-class city group[J]. Tianjin Economy, 2019(05): 3-12.

[3] Hu anjun, Sun jiuwen. A study on the development status and implementation strategies of Beijing-Tianjin-Hebei world-Class city group[J]. City,2018(06): 3-14.

[4] Han zhaozhu, Dong zhen. A study on Beijing-Tianjin- Hebei transportation integration based on holistic governance[J]. Journal of Hebei University (philosophy and social science), 2019, 44(01): 90-96.

[5] Peng xiaojing, Song guoxue. Countermeasures for hebei province to build an important base of national modern trade and logistics[J]. Journal of Hebei University (philosophy and social science), 2017, 42(03): 97-104.

[6] Li lanbing, Guo qi, Lv cheng. The construction of Xiongan new area and Beijing-Tianjin-Hebei world-class city group[J]. Nankai Journal (philosophy, literature and social science edition), 2017(04): 22-31.

[7] Zhang dini, Li lei. Winter Olympics: the opportunity and starting point of the construction of
[10] Sun minghua. Beijing-Tianjin-Hebei coordinated development: new stage, new mission, new mission [J]. Seeking Knowledge, 2019(05): 8-11.

[11] $\mathrm{Wu}$ jianzhong, Zhan shengze. The path and countermeasures of the big city disease and the non-capital function distribution of Beijing[J]. Reform of Economic System, 2018(01): 38-44.

[12] Xiao jincheng, Shen xianjie, Ma yankun. Comparison between Beijing-Tianjin-Hebei urban agglomeration and world-class urban agglomeration[J]. China Economic Report, 2017(11): 94-98.

[13] Li guoping, Song changyao. Strategic choice of high-quality development in Xiongan new area[J]. Reform, 2018(04): 47-56.

[14] Liu binglian, Sun zhe. The path of Beijing-TianjinHebei regional coordination and the Reform of Xiongan new area[J]. Nankai Journal (philosophy, literature and social science edition), 2017 (04): 12-21.

[15] Tian xuebin, Liu tianen. Innovation drives the transformation and upgrading of traditional industries in Xiongan New Area[J].Journal of Hebei University (philosophy and social science),2018,43(04):70-75.

[16] Ji lianggang. Vigorously promote the construction of Beijing-Tianjin-Hebei collaborative innovation community [N]. Hebei Daily, 2019-02-20(007).

[17] Liu hui,Jiang shixue. The enlightenment of European research area on the construction of Beijing-Tianjin-Hebei collaborative innovation community $[\mathrm{J}]$. Hebei Academic Journal,2018,38(02):157-162.

[18] Gao juan. A study on the development ideas of Xiongan new area under the background of Beijing-Tianjin-Hebei coordinated development[J]. Review of Economy and Management, 2017, 33(06): 
$130-136$.

[19] Liu xiaohui. Some understandings on the construction of "new-type urbanization and urban-rural demonstration zone" in Hebei Province[J]. Journal of Hebei University (philosophy and social science), 2017, 42(03): 81-87.

[20] Zhang gui, Liu jiqing, Li jiayu. Leading the construction of Beijing-Tianjin-Hebei world-class city cluster with Beijing-Tianjin-Xiongan innovation triangle $[\mathrm{J}]$. Journal of the Party School of Tianjin Committee of the CPC, 2019,21(01):64-70.

[21] Li lan.A study on Hebei province to promote the beijing-tianjin-hebei coordinated development[J]. Review of Economic Research, 2018(15):3-25. 